\title{
Cystatin C, oxidative stress and body fat distribution in the middle aged individuals with coronary artery disease
}

\author{
P. Srilakshmi ${ }^{1, *}$, Y V Ramakrishna Reddy ${ }^{2}$, K. Rambabu ${ }^{3}$, S. Venkat Rao ${ }^{4}$ \\ ${ }^{\mathbf{1}}$ Associate Professor, ${ }^{\mathbf{2}}$ Assistant Professor, ${ }^{3,4}$ Professor, Dept. of Biochemistry, Mamata Medical College, Khammam, \\ Telangana, India
}

*Corresponding Author: P. Srilakshmi

Email: sribiochemistry@gmail.com

Received: $15^{\text {th }}$ May, 2018

Accepted: $18^{\text {th }}$ June, 2018

\begin{abstract}
Introduction: Oxidative stress plays an important role in the progression of atherosclerosis, it is the principal cause for coronary artery disease (CAD). Lipid peroxidation product Malondialdehyde (MDA) is an index of oxidative stress. To assess the oxidative stress, MDA and total antioxidant capacity (TAC) are estimated. Body fat distribution was assessed by obesity and blood lipids, which in turn was measured by Body mass index (BMI) and waist circumference (WC). Cystatin C was measured as an emerging cardio vascular risk factor.

Materials and Methods: Study consists of two groups, 145 subjects diagnosed with CAD are included in study group and 66 age and sex matched subjects (non CAD) are included in control group.

Results: In this study, Cystatin C is highly significant observed in CAD cases than controls. BMI and WC are not significantly increased; whereas significant increase in mean MDA and decrease in mean TAC levels.

Conclusion: Oxidative stress is markedly observed in CAD cases, due to toxic effects of ROS. Increase in Cystatin C levels significantly correlated with WC in middle aged individuals.
\end{abstract}

Keywords: Coronary artery diseases, Cystatin C, Malondialdehyde, Oxidative stress, Total antioxidant capacity.

\section{Introduction}

CAD is major health burden worldwide and is the leading cause of death. It accounts one third of all deaths by 2020 , about 45 million patients will be affected with CAD in India. Atherosclerosis is fundamental cause of $\mathrm{CAD}$ in which there is an insufficient delivery of oxygen and blood to myocardium. ${ }^{1}$

Antioxidant status is a significant tool in analyzing the redox status, and is defined as the balance among oxidants and antioxidants. ${ }^{2,3}$ Oxidative stress caused due to destruction of antioxidant and pro-oxidant systems equilibrium by excess production of free radicals and decreased amounts of antioxidants. ${ }^{4}$ Free radical are highly reactive, due to one or more unpaired electrons in its orbits. ${ }^{5-7}$ The oxidants produced by cells and eosinophils, neutrophils, macrophages, tissue damage, and ischemia-reperfusion injury accounts the endogenous production. ${ }^{8,9}$ Exogenous production of radicals accounts, the ionizing, smoking, radiation, and hyperoxic environments. ${ }^{7,10,11}$ Reactive species are reactive nitrogen species and reactive oxygen species (ROS). ${ }^{12}$

Oxidative stress along with traditional risk factors, are important contributors for atherosclerosis progression and is precipitated by increased lipid peroxidation. ${ }^{13-15}$ Both oxidative stress and lipid peroxidation are implicated in the pathogenesis of early and later stages of atherosclerosis. ${ }^{16-19}$ Antioxidants can protect against free radical defense. ${ }^{20,21}$ Augmented oxidative stress leads to impairment of endothelial function in the individuals with atherosclerosis in predicting the risk for CAD. ${ }^{22}$

Cystatin C initially was used in assessing renal function. It is an inhibitor of cysteine proteases formed in all nucleated cells freely filtered in the renal glomeruli, is reabsorbed and metabolized in the proximal tubule. It also serves as a prognostic marker of $\mathrm{CAD}$ which is associated with adverse cardiovascular events in relation to hemodynamic stress, also matches with plasma levels of soluble corin and proenkephalin. ${ }^{23,24}$

\section{Materials and Methods}

The cross-sectional comparative study was conducted at Mamata Medical College and General Hospital, Khammam, Telangana, India, with the patients attending outpatient wards of cardiology and general medicine departments of hospital and local cardiac centers were included in this study. The study was approved by the institutional ethical committee. Subjects were recruited into the study randomly after obtaining the informed consent form. The individuals were separated into two group, individuals with diagnosed with $\mathrm{CAD}$ based on clinical and biochemical parameters like ECG, TMT and Cardiac Biomarkers (myocardial enzymes and troponin) were considered as cases $(\mathrm{N}=145)$ and Age and sex matched individuals without CAD recruited as control $(\mathrm{N}=66)$.

Inclusion and Exclusion Criteria: Subjects in the age group of 30-50 years. Subjects with risk factors DM, HTN and smoking were included. Alcoholics and 
Subjects with past history of CAD and Subjects on antioxidant supplementation were excluded.

Methods: Antioxidant status was evaluated by estimating the levels of MDA and TAC. MDA was measured by estimating TBARS and TAC measured as FRAP. Lipid profile was estimated using Erba XL 350 fully automated analyzer, Cystatin $\mathrm{C}$ estimated by Immuno-turbidimetry. BMI was calculated from body weight in kilograms divided by the square of the body height in meters $(\mathrm{kg} / \mathrm{m} 2)$. WC is measured at midpoint between the lower margin of last palpable rib and top of iliac crest.

\section{Statistical Analysis}

Statistical analysis was done using the software SPSS-17.0 version. t-test was done to compare the mean values. ROC analysis was done to determine the cutoff values. Pearson correlation was done to know the relation between the parameters. The results are expressed as mean \pm standard deviation (SD). $\mathrm{P}<0.05$ was considered statistically significant.

\section{Results}

In our study, we found Cystatin $\mathrm{C}$ values showed significant increase in cases compared to controls. Cystatin C marker for atherosclerosis shows its significant role in CAD. Whereas TAC and MDA value shown a significant difference, on comparison of controls with cases. The decrease in TAC and increase in MDA levels shows the rise of oxidative stress among the $\mathrm{CAD}$, and the lipid parameters like total cholesterol, triglycerides and LDL-C also showed significant difference on comparison of controls with cases, but not with HDL-C. Hence lipid profile helps in assessing the risk of CAD. The anthropometric parameters like BMI and WC has not shown any significant difference, which explains they have no role in assessing the risk for CAD (Table 1).

In the ROC analysis we found TAC and HDL having more area under curve $(0.834,0.734)$ with cutoff values of 0.74 and 41.0 respectively, which plays a role in diagnosing the risk for $\mathrm{CAD}$. Whereas Cystatin C, MDA, Total cholesterol, triglycerides, LDL-C, BMI and WC has noted very less are under curve $(<0.500)$ (Table 2, Fig. 1).

Pearson correlation was done between oxidative stress markers, with Cystatin C, lipid profile and anthropometric parameters, and we found to more significant with all the parameters except with BMI, which says that oxidative stress plays a significant role in atherosclerosis and CAD (Table 3).

Table 1: Comparison of different parameters between control and CAD cases

\begin{tabular}{|l|c|c|c|}
\hline \multicolumn{1}{|c|}{ Study Groups } & Controls & Cases & Significance \\
\hline Cystatin C $(\mathrm{mg} / \mathrm{lit})$ & 0.97 & 1.37 & $<0.05$ \\
\hline TAC $(\mu \mathrm{mol} / \mathrm{lt})$ & 0.96 & 0.64 & $<0.05$ \\
\hline MDA $(\mathrm{u} . \mathrm{mol} / \mathrm{ml})$ & 1.54 & 4.47 & $<0.05$ \\
\hline T-Chol $(\mathrm{mg} / \mathrm{dl})$ & 162.5 & 201.8 & $<0.05$ \\
\hline TG $(\mathrm{mg} / \mathrm{dl})$ & 122.2 & 162.1 & $<0.05$ \\
\hline HDL $(\mathrm{mg} / \mathrm{dl})$ & 43.18 & 39.01 & $>0.05$ \\
\hline LDL $(\mathrm{mg} / \mathrm{dl})$ & 95.17 & 129.74 & $<0.05$ \\
\hline BMI $\left(\mathrm{kg} / \mathrm{m}^{2}\right)$ & 23.36 & 24.15 & $>0.05$ \\
\hline WC $(\mathrm{cm})$ & 87.89 & 93.23 & $>0.05$ \\
\hline
\end{tabular}

Note: values expressed as mean $\pm \mathrm{SD}$, $\mathrm{p}$ value with $<0.05$ considered as significant

Table 2: ROC values of different parameters

\begin{tabular}{|l|c|c|c|c|c|c|}
\hline \multirow{2}{*}{$\begin{array}{l}\text { Test result } \\
\text { variable(s) }\end{array}$} & \multirow{2}{*}{ Sensitivity } & \multirow{2}{*}{ Specificity } & \multirow{2}{*}{$\begin{array}{c}\text { Area Under } \\
\text { Curve }\end{array}$} & \multicolumn{2}{|c|}{$\begin{array}{c}\text { Asymptotic 95\% Confidence } \\
\text { Interval }\end{array}$} & \multirow{2}{*}{$\begin{array}{c}\text { Cut-off } \\
\text { Value }\end{array}$} \\
\cline { 5 - 6 } & & & & Lower Bound & Upper bound & \\
\hline Cystatin C & 0.182 & 0.745 & 0.160 & 0.107 & 0.213 & 1.16 \\
\hline TAC & 0.742 & 0.262 & 0.834 & 0.778 & 0.889 & 0.74 \\
\hline MDA & 0.091 & 0.855 & 0.090 & 0.049 & 0.130 & 2.05 \\
\hline T-Chol & 0.303 & 0.697 & 0.264 & 0.196 & 0.331 & 173.50 \\
\hline TG & 0.288 & 0.634 & 0.267 & 0.199 & 0.335 & 143.00 \\
\hline HDL & 0.652 & 0.352 & 0.734 & 0.665 & 0.804 & 41.0 \\
\hline LDL & 0.258 & 0.683 & 0.272 & 0.203 & 0.340 & 105.5 \\
\hline BMI & 0.424 & 0.517 & 0.424 & 0.336 & 0.512 & 23.55 \\
\hline WC & 0.379 & 0.634 & 0.306 & 0.234 & 0.378 & 91.5 \\
\hline
\end{tabular}


Table 3: Correlation between oxidative stress markers, with Cystatin C, lipid profile and anthropometric parameters

\begin{tabular}{|c|c|c|c|c|c|c|c|c|}
\hline & & Cystatin C & T-Chol & TG & HDL & LDL & BMI & WC \\
\hline \multirow{2}{*}{ Cystatin C } & R.Values & 1 & $0.171^{*}$ & $0.242^{* *}$ & $-0.279^{* * *}$ & $0.158^{*}$ & 0.044 & $0.165^{*}$ \\
\hline & Sig. & - & 0.013 & 0.000 & 0.000 & 0.022 & 0.523 & 0.016 \\
\hline \multirow[t]{2}{*}{ TAC } & R.Values & $-0.282^{* *}$ & $-0.370^{* * *}$ & $-0.338^{* * *}$ & $0.238^{* *}$ & $-0.366^{\text {*** }}$ & -0.047 & $-0.177^{* *}$ \\
\hline & Sig. & 0 & 0.000 & 0.000 & 0.000 & 0.000 & 0.500 & 0.010 \\
\hline \multirow[t]{2}{*}{ MDA } & R.Values & $0.425^{* *}$ & $0.353^{* *}$ & $0.395^{* * *}$ & $-0.278^{* *}$ & $0.354^{* * *}$ & $0.164^{*}$ & $0.246^{* * *}$ \\
\hline & Sig. & 0.000 & 0.000 & 0.000 & 0.000 & 0.000 & 0.017 & 0.000 \\
\hline
\end{tabular}

Note: Pearson correlation was done

**. Correlation is significant at the 0.01 level

*. Correlation is significant at the 0.05 level.

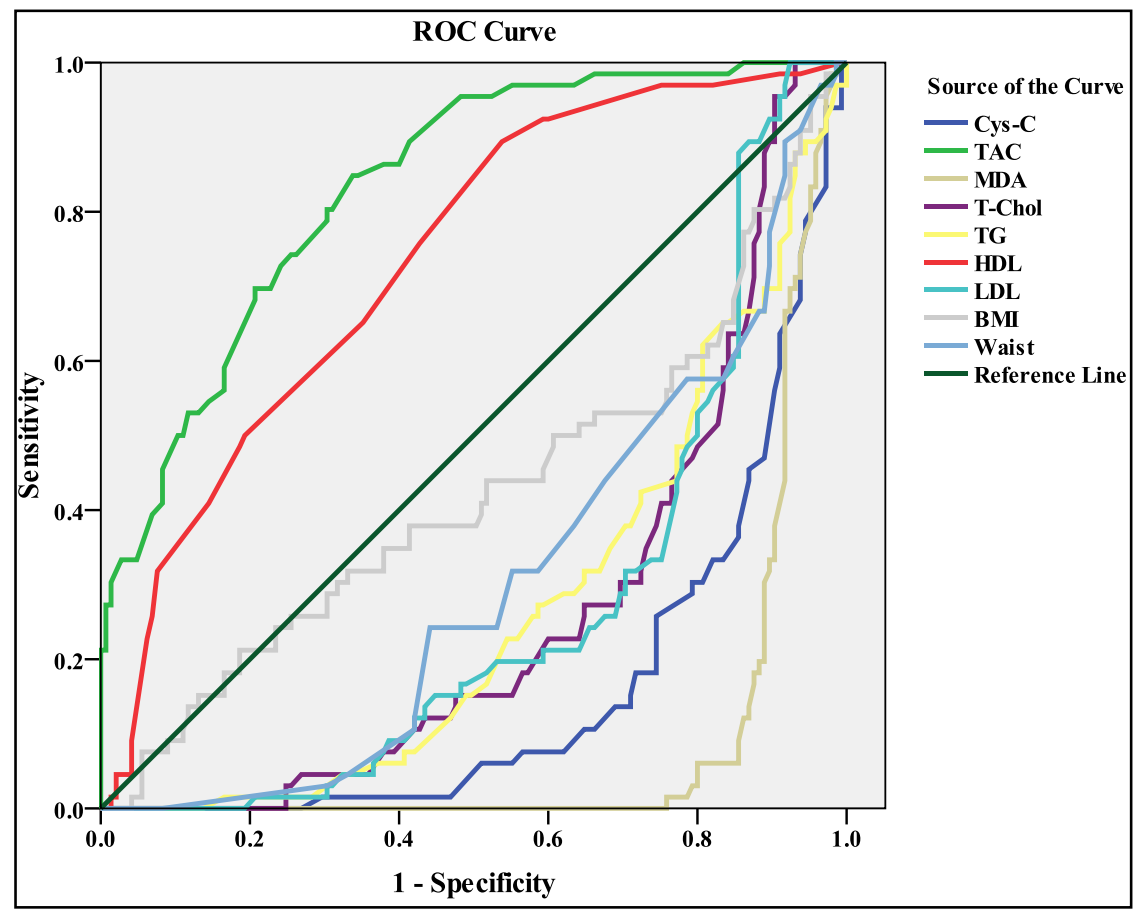

\section{Fig. 1: ROC graphical analysis}

\section{Discussion}

Increased MDA and decreased TAC levels in CAD cases explains the role of oxidative stress, which causes oxidative modification of LDL in the subintimal layer by ROS, aroused by risk factors of atherosclerosis. ROS from endothelial cells, smooth muscle cells (SMCs) and also adventitial cells, are responsible in triggering, proliferating, and migration of SMCs; oxidation of lipids; activation of metalloproteinases which are the events of atherosclerosis. ${ }^{25-27}$ The ROC analysis for TAC has shown more area under curve and pearson correlation between TAC, MDA with lipid profile, WC was highly significant, which shows the relation between oxidative stress to atherolerosis. The results were in similar with the, Murat Aydın et ${ }^{28}$ and Ali Movahed et al al. ${ }^{29}$ The presence of risk factors provokes, increase in MDA and decrease TAC levels. were observed in Similar results were reported by $\mathrm{M}$ gupta et al, ${ }^{30} \mathrm{~N}$ Patil et al. ${ }^{19}$ Increased ROS levels have toxic effect on tissues through augmented oxidation of bio-molecules and play a major role in the improvement and development of CAD. ${ }^{31}$

The study shows rise in the levels Cystatin C among the cases than controls, ROC analysis also shown more area under curve. Pearson correlation for Cystatin $\mathrm{C}$ with oxidative stress markers, lipid profile and WC are significant, which shows its role in atherosclerosis and CAD. ROS contribute to arterial oxidative stress, inflammation, and endothelial dysfunction, which have a very important role in atherogenesis and heart failure. ${ }^{32}$ Studies of, Xie L et al, 2010 colleagues, $\mathrm{H}_{2} \mathrm{O}_{2}$ induction causes elevation of cystatin $\mathrm{C}$ in the conditioned medium from cardiomyocytes. Thus, the authors suggested that cystatin $\mathrm{C}$ plays a role in cardiac extracellular matrix remodeling. ${ }^{33}$ Loew $\mathrm{M}$ et al, 2005 reported only high plasma cystatin $\mathrm{C}$ levels were associated with cardiovascular events during the follow-up. ${ }^{34}$ Recent meta-analysis by Lee $\mathrm{M}$ et al, 2010, higher cystatin C levels were strongly and independently associated with CAD. ${ }^{35}$ 
Magnusson 2013 et al, showed that abdominal obesity is significantly associated with increased baseline levels of Cystatin C. Another study illustrated a stronger correlation between Cystatin $\mathrm{C}$ and WC compared to BMI. ${ }^{36,37}$ Moreover, cystatin $\mathrm{C}$ was well expressed in human adipose tissue, subcutaneous and omental fat, says that cystatin $\mathrm{C}$ may has a role in inflammation and controlling adipose tissue mass by inhibiting cathepsins. Hence serum Cystatin C causes stability of plaques which benefits the individuals with normal kidney function. Cystatin $\mathrm{C}$ in certain range, is associated with an increased burden for plaque development. ${ }^{38}$

\section{Conclusion}

Oxidative stress due to ROS, leads to lipid peroxidation and decreased TAC which is influenced by various risk factors, was observed in CAD cases. Cystatin $\mathrm{C}$ levels are positively correlated with WC, and can be the marker to assess the risk of CAD in the middle aged individuals.

\section{References}

1. Brid NS, Raju UR, Kamat P; Initial ECG as a diagnostic tool for identification of low risk patients with chest pain. RRJMHS, 2014;3:111-114.

2. Giselli A, Serafini M, Natella F, and Scaccini C, Total antioxidant capacity as a tool assesses redox status: critical view and experimental data. Free Rad Biol Med. 2000;29:1106-14.

3. Palanisamy Pasupathi Y. Yagneswara Rao, Jawahar Farook Ganesan Saravanan, Govindaswamy Bakthavathsalam. Oxidative Stress and Cardiac Biomarkers in Patients with Acute Myocardial Infarction. Eur Jour of Scient Res. 2009;27:275-85.

4. Torun AN, Kulaksizoglu S, Kulaksizoglu M, Pramuk BO, Isbilen E, Tutuncu NB. Serum total antioxidant status and lipid peroxidation marker malondialdehyde levels in overt and subclinical hypothyroidism. Clin Endo. 2009;70:46974.

5. Koppenol WH. Names for inorganic radicals (IUPAC recommendations 2000). Pure Appl Chem. 2000;72:43746.

6. Miller DM, Buettner GR and Aust SD. Transition metals's catalysts of "autoxidation" reactions. Free Radic Biol Med. 1990;8:95-108.

7. P. Srilakshmi, MV Bhaskar, K. Rambau, MF Gopinath, GS Reddy. Oxidative stress and cystatin C in coronary artery disease. Ind Str of Res Jour. 2014;4:1-7.

8. Lopaczynski W, Zeisel SH Antioxidants, programmed cell death, and cancer. Nutr Res. 2001;21:295-307.

9. Valko M, Rhodes CJ, Moncol J, Izakovic M, Mazur M. Free radicals, metals and antioxidants in oxidative stressinduced cancer. Chem Biol Interact. 2006;160:1-40.

10. Church DF, Pryor WA Free-radical chemistry of cigarette smoke and its toxicological implications. Environ Health Perspect. 1985;64:111-26.

11. Riley PA. Free radicals in biology: oxidative stress and the effects of ionizing radiation. Int J Radiat Biol. 1994;65:27-33.

12. Afanasev IB. Competition between superoxide and hydrogen peroxide signaling in heterolytic enzymatic processes. Med Hypotheses. 2006;66:1125-128.
13. Halliwell, B. Free radicals, antioxidants and human disease: curiosity, cause, or consequences? Lancet. 1994;344:721-724.

14. Salvemini D, and Cuzzocrea, S. Therapeutic potential of superoxide dismutase mimetics as therapeutic agents in critical care medicine. Crit Care Med. 2003;31:29-38.

15. Becker, L.B. New concepts in reactive oxygen species and cardiovascular reperfusion physiology. Cardiovasc Res. 2004;61:461-470.

16. Casalone R, Granata P, Minelli E, P. Portentoso, A. Giudici, R. Righi. P. Castelli, et al. Cytogenic analysis reveals clonal proliferation of smooth muscle cells in atherosclerotic plaques. Hum Genet. 1991;87:139-143.

17. Jean-Claude Tardif, Oxidative stress and coronary heart disease. Card rounds. 2003;7:1-6.

18. Loeper, J, Goy, J, Rozenstajin, L, Bedu, O, and Moisson P. Lipid peroxidation and protective enzymes during myocardial infarction. Clin Chim Acta. 1991;15:119-25.

19. Neela Patil, Vishwas Chavan, N.D. Karnik Antioxidant status in patients with acute myocardial infarction. Ind Jour of Clinl Biochem. 2007;22:45-51.

20. Giselli, A, Serafini, M, Natella, F, and Scaccini, C. Total antioxidant capacity as a tool assesses redox status: critical view and experimental data. Free Rad Biol Med. 2000;29:1106-14.

21. Juan J. Hicks, Daniel H. Montes Cortes, Maria P. CruzDominguez, Roberto Medina-Santillan, et al.

Antioxidants decrease reperfusion induced arrhythmias in myocardial infarction with ST-elevation. Front in Biosci. 2007;12:2029-37.

22. Heitzer T, Schlinzig T, Krohn K, Meinertz T, Münzel T. Endothelial dysfunction, oxidative stress, and risk of cardiovascular events in patients with coronary artery disease. Circ. 2001;104:2673-78.

23. Xin Ying, MSa, Yan Jiang, Guangming Qin, Yafang Qian, Xiaoru Shen, Zhenyan Jiang, Shu Zheng, Zhenya Song. Association of body mass index, waist circumference, and metabolic syndrome with serum cystatin $\mathrm{C}$ in a Chinese population. Medicine. 2017;96(10);1-5.

24. Mark R. Thomas, Gregory Y.H. Lip. Novel Risk Markers and Risk Assessments for Cardiovascular Disease. Circ Res. 2017;120:133-49.

25. Gozin A, Franzini E, Andrieu V, et al. Reactive oxygen species activate focal adhesion kinase, paxillin and p130cas tyrosine phosphorylation in endothelial cells. Free Radic Biol Med. 1998;25:1021-32.

26. Madamanchi NR, Vendrov A, Runge MS. Oxidative stress and vascular disease. Arterioscler Thromb Vasc Biol. 2005;25:29-38.

27. Lum H, Roebuck KA. Oxidant stress and endothelial cell dysfunction. Am J Physiol Cell Physiol. 2001;280:71941.

28. Murat Aydın, Yusuf Selcoki, Yunus Nazl, Necmettin Colak, Kadir Serkan Yalcin, et al. Relationship between total antioxidant capacity and the severity of coronary artery disease. Jour of Clin and Exp Invest. 2012;3:22-28.

29. Ali Movahed, Dariush Iranpour, Iraj Nabipour, Mojtaba Jafari, Samad Akbarzadeh, Majid Assadi, et al. Plasma malondialdehyde, bilirubin, homocysteine and total antioxidant capacity in patients with angiographically defined coronary artery disease. Afric Jour of Biotech. 2012;12:3187-91.

30. Madhur Gupta and Suresh Chari. Proxidant and antioxidant status in patients of type II diabetes mellitus with IHD. Ind Jour of Clin Biochem. 2006;21:118-22. 
31. Sanjay Mishra, Surya Prakash Dwivedi, Ram B Singh. Role of Oxidative Stress in the Pathogenesis Progression of Coronary Artery Disease. World Hrt Jour. 2015;6:4:284-301.

32. Puddu P, Puddu GM, Cravero E, Vizioli L, Muscari A. Relationships amonghyperuricemia, endothelial dysfunction and cardiovascular disease: molecularmechanisms and clinical implications. $J$ Cardiol. 2012;59:235-42.

33. Xie L, Terrand J, Xu B, Tsaprailis G, Boyer J, Chen QM. Cystatin $C$ increases incardiac injury: a role in extracellular matrix protein modulation. Cardio Vasc Res. 2010;87:628-35.

34. L oew M, Hoffmann MM, Koenig W, Brenner H, Rothenbacher D. Genotype and plasma concentration of cystatin $\mathrm{C}$ in patients with coronary heart disease and risk for secondary cardiovascular events. Arterioscler Thromb Vasc Biol. 2005;25:1470-74.

35. Lee M, Saver JL, Huang WH, Chow J, Chang KH, Ovbiagele B. Impact of elevatedcystatin $\mathrm{C}$ level on cardiovascular disease risk in predominantly high cardiovascular risk populations: a meta-analysis. Circ Cardiovasc Qual Outcomes. 2010;3:675-83.

36. Magnusson M, Hedblad B, Engström G, et al. High levels of cystatin $\mathrm{C}$ predict the metabolic syndrome: the prospective Malmo Diet and Cancer Study. J Intern Med. 2013;274:192-99.

37. Panaich SS, Veeranna V, Bavishi C. Association of cystatin $\mathrm{C}$ with measures of obesity and its impact on cardiovascular events among healthy US adults. Metab Syndr Relat Disord. 2014;12:472-76.

38. Yufeng Wen, Dan Xia, Yanchun Wang, Huiping Zhang, Haibo Li, Gholam Ali, et al. Cystatin C is Associated With Plaque Phenotype and Plaque Burden. Kidney Blood Press Res. 2016;41:197-207.

How to cite this article: Srilakshmi P, Reddy Y V R, Rambabu K, Rao S. V. Cystatin C, oxidative stress and body fat distribution in the middle aged individuals with coronary artery disease. Int J Clin Biochem Res. 2018;5(4):622626. 